\title{
Dissecting the heterogeneity of macrophage activation syndrome
}

\author{
Sergio Davi ${ }^{1 *}$, Francesca Minoia ${ }^{1}$, AnnaCarin Horne ${ }^{2}$, Francesca Bovis ${ }^{1}$, Erkan Demirkaya ${ }^{3}$, Jonathan Akikusa ${ }^{4}$, \\ Nuray Aktay Ayaz ${ }^{5}$, Patrizia Barone ${ }^{6}$, Bianca Bica ${ }^{7}$, Isabel Bolt ${ }^{8}$, Luciana Breda ${ }^{9}$, Zane Davidsone ${ }^{10}$, \\ Carmen De Cunto $^{11}$, Jaime De Inocencio ${ }^{12}$, Sandra Enciso ${ }^{13}$, Romina Gallizzi ${ }^{14}$, Thomas Griffin ${ }^{15}$, Teresa Hennon ${ }^{16}$, \\ Gerd Horneff $^{17}$, Maka loseliani ${ }^{18}$, Michael Jeng ${ }^{19}$, Agneza Marja Kapovic ${ }^{20}$, Bianca Lattanzi ${ }^{21}$, Jeffrey M Lipton ${ }^{22}$, \\ Silvia Magni-Manzonii ${ }^{23}$, Clarissa Nassifi ${ }^{24}$, Ingrida Rumba ${ }^{10}$, Claudia Saad Magalhaes ${ }^{25}$, Sulaiman Al-Mayouf ${ }^{26}$, \\ Wafaa Mohammed Sewairi ${ }^{26}$, Kimo C Stine ${ }^{27}$, Olga Vougiouka ${ }^{28}$, Lehn Weaver ${ }^{29}$, Mabruka Ahmed Zletni ${ }^{30}$, \\ Nicola Ruperto ${ }^{1}$, Alberto Martini ${ }^{1}$, Randy Q Cron ${ }^{31}$, Angelo Ravelli ${ }^{1}$
}

From 21st European Pediatric Rheumatology (PReS) Congress

Belgrade, Serbia. 17-21 September 2014

\section{Introduction}

Macrophage activations syndrome (MAS) in systemic juvenile idiopathic arthritis (sJIA) can pursue a rapidly fatal course. However, diagnosis is often challenging as MAS may be mimicked by confusable conditions, such as flares of sJIA or systemic infections. In addition, the clinical spectrum of MAS is known to be heterogeneous.

\section{Objectives}

To seek insights into the heterogeneity of MAS by comparing characteristics of patients enrolled in a large multinational survey in relation to geographic origin, specialty of attending physician, detection of hemophagocytosis (HP), and outcome.

\section{Methods}

Patient data were collected retrospectively by pediatric rheumatologists (PR) or pediatric hemato-oncologists (PHO). Clinical features, treatments and outcome were compared between groups by Mann-Whitney or chisquare tests. "Severe course" was defined as ICU admission or death.

\section{Results}

362 patients with MAS in sJIA were collected by 95 investigators from 33 countries. 179 patients (49.4\%) were enrolled in Europe (EU), 72 (19.9\%) in North America (NA) and 111 (30.7\%) in other continents

${ }^{1}$ Istituto G. Gaslini, Genova, Italy

Full list of author information is available at the end of the article
(OC). 79 (21.8\%) patients were included by PHO. HP was detected in $44 \%$ of patients and was not detected or looked for in 56\%. Severe course was reported in 92 (25\%) patients. Comparison by geographic origin showed a lower frequency of CNS disease in EU patients. NA physicians used more frequently ivIg and biologics. Patients entered by $\mathrm{PHO}$ had greater frequency of multiorgan failure and were given more commonly biologics and etoposide, whereas PR used more frequently cyclosporine (CsA). Patients with HP had shorter duration of sJIA at MAS onset, higher prevalence of hepatosplenomegaly, lower levels of platelets and fibrinogen and received more frequently CsA, ivIg and etoposide. Patients with severe course were older, had longer duration of sJIA at MAS onset, greater frequency of haemorrhages and CNS dysfunction, lower levels of ESR, albumin and fibrinogen, higher levels of LDH and D-dimer and were treated more commonly with CsA, ivIg and etoposide.

\section{Conclusion}

Clinical and histopathologic features of MAS in sJIA were overall comparable among patients from different continents, whereas there was disparity in therapeutic choices made by specialists practicing in different geographic areas or fields. Patients with detection of HP or severe course had more acute clinical picture and were treated more aggressively.

\section{Disclosure of interest}

None declared. 


\section{Authors' details}

${ }^{1}$ Istituto G. Gaslini, Genova, Italy. ${ }^{2}$ Investigator Consortium for MAS

Classification Criteria (ICMCC), Stockholm, Sweden. ${ }^{3}$ ICMCC, Ankara, Turkey.

${ }^{4}$ ICMCC, Melbourne, Australia. ${ }^{5}$ ICMCC, Istanbul, Turkey. ${ }^{6}$ ICMCC, Catania, Italy.

${ }^{7}$ ICMCC, Rio de Janeiro, Brazil. ${ }^{8}$ ICMCC, Zurich, Switzerland. ${ }^{9}$ ICMCC, Chieti,

Ital. ${ }^{10}$ ICMCC, Riga, Latvia. ${ }^{11}$ ICMCC, Buenos Aires, Argentina. ${ }^{12}$ ICMCC,

Madrid, Spain. ${ }^{13}$ ICMCC, Mexico City, Mexico. ${ }^{14}$ ICMCC, Messina, Italy.

${ }^{15}$ ICMCC, Charlotte, USA. ${ }^{16}$ ICMCC, Buffalo, USA. ${ }^{17}$ ICMCC, Sankt Augustin, Germany. ${ }^{18}$ ICMCC, Tbilisi, Georgia. ${ }^{19}$ ICMCC, Stanford, USA. ${ }^{20}$ ICMCC, Zagreb, Croatia. ${ }^{21}$ ICMCC, Ancona, Italy. ${ }^{22}$ ICMCC, New York, USA. ${ }^{23}$ ICMCC, Roma, Italy. ${ }^{24}$ ICMCC, Belo Horizonte. ${ }^{25}$ ICMCC, Botucatu, Brazil. ${ }^{26}$ ICMCC, Riyadh, Saudi Arabia. ${ }^{27}$ ICMCC, Little Rock, USA. ${ }^{28}$ ICMCC, Athens, Greece. ${ }^{29}$ ICMCC, Philadelphia, USA. ${ }^{30}$ ICMCC, Tripoli, Libya. ${ }^{31}$ ICMCC, Birmingham, USA.

Published: 17 September 2014

doi:10.1186/1546-0096-12-S1-P54

Cite this article as: Davi et al: Dissecting the heterogeneity of macrophage activation syndrome. Pediatric Rheumatology 2014 12(Suppl 1):P54.

\section{Submit your next manuscript to BioMed Central} and take full advantage of:

- Convenient online submission

- Thorough peer review

- No space constraints or color figure charges

- Immediate publication on acceptance

- Inclusion in PubMed, CAS, Scopus and Google Scholar

- Research which is freely available for redistribution

Submit your manuscript at www.biomedcentral.com/submit
Ciomed Central 